\title{
Wishful thinking and source monitoring
}

\author{
RUTHANNA GORDON \\ Illinois Institute of Technology, Chicago, Illinois \\ and \\ NANCY FRANKLIN and JENNIFER BECK \\ State University of New York, Stony Brook, New York
}

\begin{abstract}
Memory distortions sometimes serve a purpose: It may be in our interest to misremember some details of an event or to forget others altogether. The present work examines whether a similar phenomenon occurs for source attribution. Given that the source of a memory provides information about the accuracy of its content, people may be biased toward source attributions that are consistent with desired accuracy. In Experiment 1, participants read desirable and undesirable predictions made by sources differing in their a priori reliability and showed a wishful thinking bias-that is, a bias to attribute desirable predictions to the reliable source and undesirable predictions to the unreliable source. Experiment 2 showed that this wishful thinking effect depends on retrieval processes. Experiment 3 showed that under some circumstances, wishes concerning one event can produce systematic source memory errors for others.
\end{abstract}

The origin of a message-hence, the origin of one's memory for it - is often diagnostic of how trustworthy the message's content is. Information about the reliability of a new car deserves different treatment if read in a Consumer Reports article than if read in a magazine ad or an e-mail from a friend. According to the source monitoring framework of Johnson and colleagues (Johnson, Hashtroudi, \& Lindsay, 1993; Johnson \& Raye, 1981), memories typically are not explicitly tagged with source information. Rather, cues intrinsic to the memory are used to reconstruct its source. A memory of reading large print with lots of exclamation points would, for example, be a cue that the information about the car had come from a magazine ad.

Several types of cues are used to identify a memory's source, such as perceptual details about the remembered event and information about the cognitive processes that occurred when the memory was created (Johnson, Foley, Suengas, \& Raye, 1988). For the most part, people attribute memories to the source for which the qualities of the memory's features (e.g., vividness) are most characteristic (see Johnson et al., 1993, for a review). Although source monitoring can occasionally be inaccurate, it seems

We thank Glenda Villareal for her help with stimulus construction; Dan Bashari, Camilla Lo, Frank Yao, Mat Williams, and Sheila Hermanowski for their assistance in running the studies; and Larry Jacoby, Colleen Kelley, Richard Gerrig, Susan Brennan, Mara Mather, and three anonymous reviewers for their helpful comments on this article. Correspondence relating to this article can be sent to R. Gordon, Institute of Psychology, Illinois Institute of Technology, 3101 South Dearborn, Suite 252, Chicago, IL 60616-3793, or to N. Franklin, Department of Psychology, State University of New York, Stony Brook, NY 11794-2500 (e-mail: gordonr@iit.edu or nfranklin@notes.cc.sunysb.edu). to be designed to operate in a sensible manner, by relying on features with values empirically correlated with the various candidate sources (e.g., Intraub \& Hoffman, 1992; Johnson, Foley, \& Leach, 1988).

However, source monitoring doesn't always produce accurate attributions. Previous work has shown that cases of inaccuracy typically derive from the use of otherwise appropriate heuristics on anomalous items, such as particularly vivid mental images (Johnson \& Raye, 1981), invalid schematic information (Sherman \& Bessenoff, 1999), or guessing errors. Even a system that is designed to make rational decisions sometimes produces errors. The present work addresses one way in which source attributions may be influenced by goals other than accuracy. That is, we have identified a factor that systematically contributes to the decision despite being uncorrelated with source.

Consider again that you are trying to identify the source of your memory for information about a car. It may be that you encountered this information as a casual reader and have no vested interest in the car's quality. In that case, you would probably use intrinsic characteristics of the memory, as described above, to make a source attribution.

Alternatively, you may have a vested interest in the car's quality (for example, because you've just bought one). If source monitoring is affected by a wishful thinking bias, your desire to own a good car might lead you to attribute the rave review to a reliable source, like a Consumer Reports article. Similarly, and for the same reason, you might be biased to attribute a negative review to an ad from a competing company.

Certainly, accuracy in source monitoring serves people's best interests. Even if accurate source decisions have unpleasant implications, they generally can guide our beliefs and actions most appropriately. However, we 
have an additional need for beliefs, perceptions, and memories that support an optimistic worldview. Undesirable but accurate judgments serve our need to form a correct model of the universe, whereas desirable but inaccurate judgments serve other needs of mental selfpreservation.

A brief look across different literatures on cognition suggests a broad influence of desire on information processing. Desire can affect what we remember, as with selective distortions in memory for poor grades (Bahrick, Hall, \& Berger, 1996) or choice-supportive effects (Dellarosa \& Bourne, 1984; Greene, 1981; Mather \& Johnson, 2000; Mather, Shafir, \& Johnson, 2000). In both of these examples, memory is distorted to make it appear that past performance or judgment was better than it actually was (see also Greenwald, 1980; Ross, McFarland, $\&$ Fletcher, 1981). People are also more likely to retrieve accurate information when it is consistent with their wishes and less likely when it is not (Woike \& Polo, 2001). Desire also extends to cognitive processes other than memory, including perception (Boon \& Davies, 1996), likelihood estimation (Perloff \& Fetzer, 1986; Taylor, 1989; Weinstein \& Klein, 1996), and judgment (Ditto, Jemmott, \& Darley, 1988; see also Kunda, 1990, for a review).

Thus, wishful thinking in its various forms pervades cognition. It is reasonable, then, to wonder whether desirebased distortions affect source memory. A small number of studies point toward such a possibility. Morrison and Haddock (1997) have shown a bias to attribute negative thoughts to an internal source and positive thoughts to an external source. It may be in our interest to attribute negative messages to private thoughts, whereas positive messages may have more ego-boosting value if remembered as originating elsewhere (see also Bentall, 1990). However, this finding could also reflect a rational heuristic: Politeness may bias the statements of those around us in a positive direction, but no such filter limits our internal monologues.

More support for the role of wishful thinking in source monitoring comes from unconscious plagiarism paradigms. Participants falsely attribute other people's ideas to themselves under some circumstances (Marsh, Landau, \& Hicks, 1997), and this error may arise because people want to believe that they and not others were the source of good ideas. A direct test of this hypothesis, however, would require a comparison of source accuracy between ideas of varying quality, and to our knowledge this factor has not been directly manipulated.

Mather et al. (2000) have shown that after deciding between two options, people make choice-supportive source misattributions. Participants were asked, for example, to choose between two job candidates, each with an equal number of positive and negative qualities. Afterward, they tended to attribute more positive qualities to the chosen option and sometimes attributed more negative qualities to the rejected option. The desire to have made a good decision may have mediated the effect, but this possibility is confounded with another: Participants may have a source monitoring heuristic suggesting that they usually choose the better of two options. Indeed, when the choice between options is made by the experimenter rather than the participant, the effect disappears (Mather, Shafir, \& Johnson, 2003).

To illustrate the purpose of the present work and its potential value better, imagine that you are a cancer patient and that you have read an article in the National Enquirer about a new "miracle cure" that eliminates cancers entirely. You wish the story were true, but you know that the Enquirer is an unreliable source. Later, the desire to believe that the story was accurate may cause you to recall the source as the New York Times. It is understandable that the need for self-protection and for hope might lead you to this error. Using much less dramatic scenarios, Experiment 1 sought to create circumstances in which such a bias might emerge. Experiment 2 explored possible loci of the effect at encoding and at retrieval. Once the basic effect was established in Experiments 1 and 2, Experiment 3 tested how indirectly and how broadly wishful thinking may influence memory.

\section{EXPERIMENT 1 Establishing the Effect}

Experiment 1 tested for a wishful thinking bias by using two sources of differing accuracy who made predictions that were either desirable, undesirable, or neutral. After a delay, participants attempted to recall the source of each prediction.

In order to induce participants to wish that one or the other source had produced the different predictions, but also in an effort to equate the two in their global degree of expertise, we used two fictitious psychics as sources. We manipulated their reliability, with one having a high and the other a low overall hit rate in their predictions. Wishful thinking would be demonstrated if people were biased to attribute desirable predictions to the reliable psychic and undesirable predictions to the unreliable psychic, regardless of the actual source.

\section{Method}

Participants. Thirty-six undergraduates at SUNY Stony Brook received course research credit or $\$ 7$ compensation for participating in a single 1.5-h session. All were fluent speakers of English.

Materials and Design. An introductory paragraph, read by all participants, described one psychic, Anna Ashland, as highly reliable ( $80 \%$ correct across her predictions) and another psychic, Candy Carson, as highly unreliable ( $20 \%$ correct). (See Appendix A.)

Twenty scenarios followed the introductory paragraph and preceded the critical items. These were similar in construction but not in content to the experimental scenarios. Each scenario consisted of one to three sentences describing the current status of a situation, followed by a sentence in which one of the psychics predicted an outcome. These scenarios (unlike the critical items shown later) ended with a sentence describing the actual outcome of the situation. For the reliable psychic (Anna), 8 predictions were borne out and 2 were not, but for the unreliable psychic (Candy), the opposite distribution held. These scenarios were intended to provide evi- 
dence to the participants for the stated accuracies of the two psychics. For these premanipulation paragraphs, each psychic made the same number of desirable, undesirable, and neutral predictions. (See description of norming below.) Each also made the same number of predictions that were established through norming to be of high, low, or neutral likelihood.

Of the 30 critical scenarios, 10 were neutral, inducing no preference concerning outcome. Two versions of each of the other 20 critical scenarios were created. Each version ended with the same prediction, but the described situation leading to the prediction differed. One version was designed to bias the participants to prefer the predicted outcome (desirable bias), and the other biased them to prefer that the prediction not be borne out (undesirable bias). (See Appendix A for examples.) Half of the scenarios involved predictions that something would happen and half that something would not happen. No outcomes were given for the critical scenarios.

Norming. Premanipulation and critical paragraphs were normed by 16 additional SUNY Stony Brook undergraduates, also fluent English speakers. Each saw all of the neutral critical stimuli and one version of each of the biased critical stimuli. Each also saw all of the premanipulation scenarios, with the outcomes removed to keep the format consistent. These new participants rated each prediction for desirability on a scale from 1 to 7 , with 1 being definitely don't want this to happen and 7 being definitely want this to happen. They also rated each prediction from 1 to 7 for likelihood, with 1 being impossible and 7 being certain. The order of these tasks was counterbalanced across participants. All neutral predictions used in Experiment 1 had a median normed desirability of 4 (no preference). For biased predictions, all desirable versions used in Experiment 1 had a median rating of 5 or more, and all undesirable versions had a median of 3 or less. Median likelihood ratings for desirable and undesirable versions did not differ by more than 2 points.

Procedures. At the beginning of the experiment, the participants saw the introductory paragraph, followed by the 20 premanipulation scenarios. Order of scenario presentation was randomized. The participants read at their own pace.

The participants were next presented with the 30 critical stimuli in random order. Each was shown 10 scenarios written with a desirable prediction, 10 written with an undesirable prediction, and 10 that were neutral. For each type of scenario, half were made by the reliable psychic and half by the unreliable psychic. The participants read at their own pace and pressed a button to advance to the next paragraph.

After reading the experimental scenarios, the participants performed an unrelated task for half an hour. They then saw in random order the experimental paragraphs that they had seen previously. The paragraphs were presented in their entirety, except that a single asterisk replaced the predicting psychic's name. For each scenario, they were asked to press one button if Anna Ashland had made the prediction and another if Candy Carson had made it. No feedback was given for these responses.

\section{Results and Discussion}

To reiterate, a wishful thinking effect would be manifested not as an overall accuracy difference between the reliable and the unreliable psychics, nor as an overall difference between desirable and undesirable predictions, but as the interaction of the two. That is, wishful thinking would be manifested as the tendency to attribute desirable predictions to the reliable psychic (thus raising their likelihood of being realized) and undesirable predictions to the unreliable one (thus lowering that likelihood).

Means and standard deviations for source accuracy are shown in Table 1. An analysis of variance (ANOVA)
Table 1

Means and Standard Deviations for Source Accuracy in Experiment 1

\begin{tabular}{|c|c|c|c|c|c|c|}
\hline \multirow[b]{2}{*}{ Psychic } & \multicolumn{2}{|c|}{ Desirable } & \multicolumn{2}{|c|}{ Neutral } & \multicolumn{2}{|c|}{ Undesirable } \\
\hline & $M$ & $S D$ & $M$ & $S D$ & $M$ & $S D$ \\
\hline Anna & $.73^{*}$ & $.25^{*}$ & .66 & .25 & $.60^{\dagger}$ & $.29^{\dagger}$ \\
\hline Candy & $.57^{\dagger}$ & . $24^{\dagger}$ & .62 & .19 & $.68^{*}$ & $.21^{*}$ \\
\hline
\end{tabular}

${ }^{*}$ Wish-consistent conditions. †Wish-inconsistent conditions.

showed a significant interaction between predicting psychic (Anna or Candy) and desirability (desirable, neutral, or undesirable prediction, defined as a function of the scenario's setup) $\left[F(2,70)=4.09, M S_{\mathrm{e}}=0.26, p=\right.$ $.021]$. A post hoc polynomial contrast showed the linear relationship predicted by the wishful thinking effect, a significant trend in which accuracy was higher in the wish-consistent cases, when Anna predicted a desirable outcome or Candy predicted an undesirable outcome, than in the wish-inconsistent cases, with neutral items in between $\left[F(1,35)=7.94, M S_{\mathrm{e}}=0.53, p=.008\right]$.

Although the predicted interaction was found, neither main effect was significant [for psychic, $F(1,35)=1.73$; for bias, $F(2,70)=0.05]$. That is, scenarios whose predicted outcomes (independent of the psychic) were desirable $(M=.65)$, neutral $(M=.64)$, or undesirable $(M=$ .66) did not produce significantly different source accuracy, nor did scenarios in which the original predictor was Anna $(M=.67)$ or Candy $(M=.62)$. This pattern of data supports the presence of wishful thinking, in that what matters is the interaction of an outcome's desirability and the likelihood that it will occur (as embodied by the predicting psychic). An undesirable outcome predicted by a bad psychic can serve wishful thinking as well as a desirable outcome predicted by a good psychic.

Wishful thinking does appear to affect source monitoring. Source accuracy increases when desirable outcomes are predicted by reliable sources or when undesirable outcomes are predicted by unreliable sources, and it is systematically undermined when undesirable outcomes are predicted by reliable sources or when desirable outcomes are predicted by unreliable sources. The improvement in accuracy when desire and source are consistent indicates that wishful thinking does not merely interfere with normal source monitoring but can contribute systematically to source decisions.

\section{EXPERIMENT 2 The Locus of the Wishful Thinking Effect}

The wishful thinking effect might reflect actual memorial processes: Desire-inconsistent scenarios may be processed or stored differently from desire-consistent ones. For example, when participants are encoding the original desire-inconsistent scenarios, they might also imagine a variety of wished-for counterfactual scenarios, or they might encode these scenarios less strongly than desireconsistent ones. Either of these encoding processes would make accurate source attribution more difficult later. 
Alternatively, wishful thinking may lead to a decision bias at test. Participants might use their desire as a cue to source along with more rational cues. This would make them particularly vulnerable to wishful thinking under the present paradigm, in which few cues actually distinguish between predictions made by the two sources. When participants are uncertain of the correct source, desire may bias their guessing strategies. It is also possible, of course, that some combination of encoding and retrieval processes contributes to the effect.

In Experiment 2, half of the participants were aware of the accuracy of the two sources at encoding, making them functionally equivalent to the participants in Experiment 1 . The other half did not receive this information until just before test. For them, the source had an implication for outcome likelihood at retrieval but not at encoding. If the retrieval group did not show a wishful thinking effect, this would indicate that the effect depended on encoding processes. Such encoding processes might work either in isolation or in concert with retrieval processes, but retrieval processes alone would not be sufficient. If, on the other hand, both groups showed a wishful thinking effect, that would indicate that retrieval processes alone were sufficient to produce the effect.

\section{Method}

Participants. The participants were 68 undergraduates at SUNY Stony Brook (35 in the encoding condition, 33 in the retrieval condition) who received $\$ 10$ or $1 \mathrm{~h}$ of course research credit for participating in a single 1-h session. All were fluent English speakers, and each participant was assigned at random to one of the two task conditions.

Materials. Materials were the same as those in Experiment 1, with some modifications. Premanipulation scenarios, with outcomes given, were not used-source accuracy information was given only through direct statements in both conditions. In addition, 12 new scenarios ( 4 positive, 4 negative, and 4 neutral) were added to the test so that old-new accuracy could be differentiated from source monitoring accuracy.

Procedures. The participants first read an introduction describing the two sources. For the encoding condition, these paragraphs were similar to those in Experiment 1. The participants were informed that Anna Ashland was highly accurate and that Candy Carson was highly inaccurate.

The participants in the retrieval condition were told that although the hotline had recently begun to collect accuracy data, figures were not yet in for either psychic. For these participants, it was not apparent during study that either psychic's predictions were more likely to come true.

All participants then read the 30 critical scenarios one at a time, at their own pace, and then performed a 20-min distractor task. At the end of this time, the participants in the retrieval condition were told that the hotline had finished collecting accuracy data and were informed of the relative accuracy of the two psychics.

All participants next saw the 30 old scenarios presented in random order, with source names replaced by asterisks. These were intermixed with 12 new scenarios, also with asterisks in place of source names. For each scenario, the participants pressed one button if Anna Ashland had made the prediction, another if Candy Carson had, and a third if the prediction was new. No feedback was given.

\section{Results and Discussion}

If wishful thinking affects memory only through processes at encoding, then the encoding but not the re- trieval condition should produce results similar to those in Experiment 1. If retrieval processes alone are sufficient to produce a wishful thinking effect, then the encoding condition (in which source accuracy information was available before study) and the retrieval condition (in which accuracy information was given just prior to test) should both show such a pattern.

Old-new accuracy (correctly identifying new predictions as new and attributing old predictions to one of the psychics) did not differ significantly between the encoding and retrieval conditions $[t(66)=0.023, p=.982]$. In fact, recognition was quite good overall; mean old-new accuracy was .92 .

Means and standard deviations for source accuracy in each condition are shown in Table 2. Source accuracy was calculated as the proportion of scenarios correctly identified as old that were attributed to the correct source. The psychic $\times$ desirability interaction was significant $\left[F(2,132)=8.765, M S_{\mathrm{e}}=0.703, p<.001\right]$. This reflects a wishful thinking effect in which participants showed higher source monitoring accuracy for negative predictions from an unreliable source and positive predictions from a reliable source than for the two wishinconsistent conditions. This pattern was present for both the encoding and retrieval conditions, and there was no significant difference in the level of the effect between the two conditions $[F(2,65)=1.36, p=.265]$. Accuracy for the neutral predictions fell between these two extremes, although in the encoding condition it tended to be closer to the levels for wish-consistent predictions. The wishful thinking effect appears to survive even when source accuracy information is available only at retrieval.

A significant effect of condition $[F(1,66)=9.179$, $\left.M S_{\mathrm{e}}=1.126, p=.003\right]$ reflects an advantage in overall source monitoring ability in the encoding condition $(M=$ .63 vs. $M=.53$ for the retrieval condition). This is sensible, given that the information provided about the two sources before study in this condition would make them more discriminable. The psychic $\times$ condition interaction reached significance $[F(1,66)=4.045, p=.048]$, reflecting a pattern in which source monitoring is slightly better for the accurate psychic (Anna) than for the inaccurate psychic (Candy) in the retrieval condition. It is unclear why this effect might occur for the retrieval participants, since for them no differences existed between

Table 2

Means and Standard Deviations for Source Accuracy in Experiment 2

\begin{tabular}{|c|c|c|c|c|c|c|}
\hline \multirow[b]{2}{*}{ Condition } & \multicolumn{2}{|c|}{ Desirable } & \multicolumn{2}{|c|}{ Neutral } & \multicolumn{2}{|c|}{ Undesirable } \\
\hline & $M$ & $S D$ & $M$ & $\overline{S D}$ & $M$ & $S D$ \\
\hline \multicolumn{7}{|l|}{ Encoding } \\
\hline Anna & $.65^{*}$ & $.27^{*}$ & .66 & .26 & $.56^{\dagger}$ & $.25^{\dagger}$ \\
\hline Candy & $.59^{\dagger}$ & $.27^{\dagger}$ & .66 & .31 & $.68^{*}$ & $.26^{*}$ \\
\hline \multicolumn{7}{|l|}{ Retrieval } \\
\hline Anna & $.65^{*}$ & $.25^{*}$ & .56 & .27 & $.46^{\dagger}$ & $.28^{\dagger}$ \\
\hline Candy & $.43^{\dagger}$ & $.28^{\dagger}$ & .44 & .24 & $.62^{*}$ & $.24^{*}$ \\
\hline
\end{tabular}

*Wish-consistent conditions. †Wish-inconsistent conditions. 
the psychics at encoding that might lead to differences in source memory strength between the two.

It appears that the wishful thinking effect is due not to differences in the encoding of wish-consistent and wish-inconsistent scenarios, but to a bias at retrieval. This is consistent with other, related phenomena, such as choice-supportive memory (Mather \& Johnson, 2000; Mather et al., 2000) and schema-based halo/devil effects (Cooke, Marsh, \& Hicks, 2003). It may be that when people recognize a scenario as old but are not certain of the source, they use information about their own desires as a cue and attribute the scenario to a wish-consistent source. As with other forms of desire-based reasoning, in this case people would make wished-for conclusions in much the same way as they normally make accurate conclusions. Alternatively, people may sometimes ignore rational cues to source when retrieving a wish-inconsistent scenario. If one possible source supports their desires, they may raise the threshold for accepting evidence for the wish-inconsistent source.

\section{Signal Detection Analysis}

Experiment 2 gives behavioral evidence that wishful thinking affects source monitoring through a retrieval bias. However, its results still leave open the possibility that although encoding processes are not necessary, they might contribute to the effect when credibility information is available prior to study. We performed a signal detection analysis on Experiments 1 and 2 both to provide corroboration for the existence of a retrieval bias and to determine whether any recollection-based processes might be at work in the encoding condition that were not at work in the retrieval condition. Significant differences in $d^{\prime}$, a measure of discrimination, would reflect differences in the level of recollective processes contributing to source monitoring for wish-consistent and -inconsistent scenarios. Differences in the criterion $C$ would reflect biases at retrieval such as those suggested in Experiment 2. Given the behavioral evidence that the effect is bias based, we would expect differences in $C$ between positively and negatively valenced scenarios for both experiments, and across both conditions of Experiment 2 .

Since the same conclusions could be determined by analyzing attributions to either source, we arbitrarily chose to analyze responses for the reliable source (Anna Ashland). The number of correct source attributions, out of the number of Anna's scenarios attributed to either old source, were considered "hits." Incorrect attributions of Candy's scenarios to Anna were considered "false alarms." Since cells with values of 1 or 0 result in infinite values for both $d^{\prime}$ and $C$, an adjustment was performed on these numbers by transforming proportion $X / N$ (where $X$ is the number correct and $N$ is the number of trials) to $(X+.5) /$ $(N+1)$ (after Hautus, 1995, and Miller, 1996, cited in Macmillan \& Creelman, 2004).

Table 3 summarizes the $d^{\prime}$ and $C$ measures for each experiment. An ANOVA conducted on these measures for Experiment 1 showed no significant differences in $d^{\prime}$
$[F(2,70)=0.13, p=.88]$ but did show significant differences in $C[F(2,70)=4.14, p=.02]$. Table 3 shows that the criterion is at its most negative value for desirable predictions (indicating a bias to attribute these scenarios to the reliable source) and at its most positive value for undesirable predictions (indicating a bias to attribute these scenarios to the unreliable source).

For Experiment 2, an ANOVA showed no significant differences in $d^{\prime}$ based on stimulus type $[F(2,132)=$ $0.014, p=.99]$, but there was a significant difference in $d^{\prime}$ between conditions $[F(1,66)=8.618, p=.005]$. This difference appears to reflect increased discriminability of the two sources across stimulus types in the encoding condition relative to the retrieval condition. This makes sense, given that in the retrieval condition, the two sources differed only in name during learning, whereas additional information discriminated them in the encoding condition. There were significant differences in $C$ based on stimulus type $[F(2,132)=8.337, p<.001]$, paralleling the pattern found for Experiment 1 . There were marginally significant differences in $C$ between conditions $[F(1,66)=$ $3.421, p=.069$ ], reflecting a slightly stronger bias in the retrieval condition than in the encoding condition. Given that participants in the encoding condition may have had more discriminatory cues to work with, this difference in bias strength also makes sense.

Taken together, these signal detection analyses provide additional evidence for a retrieval bias toward attributing desirable predictions to a reliable source and undesirable predictions to an unreliable source.

\section{EXPERIMENT 3 Distorting Unrelated Memories Through Wishful Thinking}

Experiments 1 and 2 show that wishful thinking concerning an event or message can lead to memory distortion specifically for that item. But there are other ways in which one's wishes could be served through source memory. If the memory for the source of a particular item is strong, but so are the desires related to that item, then whole sets of other memories involving that source might be distorted even if these memories are not directly related in content to the desires. The relevance of these other memories to the likelihood that one's wishes will be realized may be more important than their content.

For a dramatic example, consider the following: Imagine that it is the morning of September 11, 2001. You

Table 3

Mean Signal Detection Measures of Discriminability $\left(d^{\prime}\right)$ and Bias $(C)$ in Experiments 1 and 2

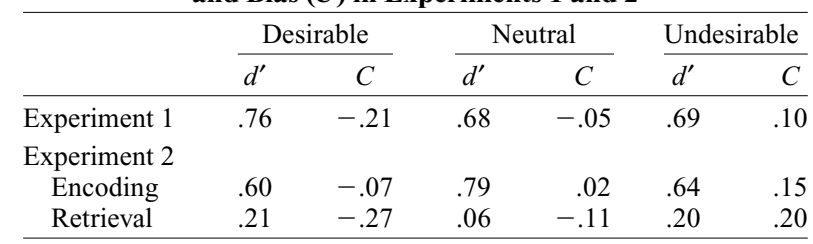


know of four airplanes that have been hijacked, and you are anxiously awaiting news that will clarify what is happening. An acquaintance tells you that in addition to the four, several other airplanes have been hijacked and are now being flown toward additional targets. You may have little a priori reason to consider this acquaintance a particularly reliable or unreliable source. Given your strong wish for her message to be wrong, however, you are motivated to establish her as an unreliable source. In doing so, you may be biased to remember previous inaccurate messages with uncertain sources as having come from her. Wishful thinking about a single message or event could potentially lead to distortion of a whole database of memories for events that have no direct relation to the current one, other than their relevance to source reliability. Experiment 3 tested this possibility.

\section{Method}

Participants. Sixty-two undergraduates at SUNY Stony Brook received course research credit for participating in a single $1.5-\mathrm{h}$ session. All were fluent speakers of English.

Materials. Experiment 3 used two kinds of to-be-learned scenarios. (See Appendix B for examples of both types.) The critical stimuli (that is, those for which we predicted errors in a subsequent source memory task) were 48 brief and unrelated stories. These scenarios were constructed using a format similar to those from the first two experiments, save that a final sentence indicated whether the prediction had been correct.

Of the 24 scenarios learned for each psychic (Heather Heartly and Deanna Divine), 8 were mildly positive (that is, the psychic predicted that something normed as slightly better than neutral would happen or that something slightly worse than neutral would not happen), 8 were mildly negative, and 8 were neutral. Within each of these categories, half of the predictions were correct and half were incorrect. That is, in reality, neither psychic was more accurate than the other, or more accurate than chance, and neither was more positive than the other in terms of either the predictions she made or the outcomes associated with her.

The valence of these scenarios was determined through a norming study that used participants who had not been involved in Experiments $1-3$. Norming participants were given each scenario, with the outcome removed. They then rated how much they wanted the prediction to come true on a seven-point scale with 1 low and 7 high. Positive scenarios had a mean rating of 4.6, negative scenarios a mean rating of 3.3, and neutral scenarios a mean rating of 3.9. Although the positive, negative, and neutral categories could be distinguished by their desirability, these scenarios were written to produce much weaker desires than those used in Experiments 1 and 2.

The second category of to-be-learned scenarios was intended to elicit much stronger wishes. There were only two of these major scenarios, one from each source. These were judged by the participants in the norming study to have valences on a seven-point scale of 1.4 (the negative scenario) and 6.5 (positive scenario) and did not include outcomes.

Each psychic was associated with the highly desirable major prediction for half of the participants. In order to increase the likelihood that the participants would remember which psychic made which major prediction (which is essential for the effect we want to study), each major scenario mentioned the relevant psychic several times when discussing her prediction. We predicted that participants' strong wishes concerning the accuracy of these predictions would affect memory for the minor scenarios, leading correct minor predictions to be attributed to the source of the desirable major prediction and incorrect minor predictions to be attributed to the source of the undesirable major prediction.
Twenty-four new items were constructed for the test phase. They followed the same design and were drawn from the same item pool as the old items.

Procedure. The participants were told to read all scenarios carefully in preparation for an unspecified test. They then read the minor scenarios in random order, one at a time, at their own pace. Afterward, they read the two major predictions, also in random order.

The two major scenarios were each associated with several immediate follow-up tasks. First, we asked, "How much do you want [psychic's] prediction, [reiteration of prediction], to come true?" The participants gave their response on a scale of 1 (not at all) to 7 (very much). Next, seven "trivia" questions were presented one at a time. For each question, the participants selected from two alternatives, and feedback about the correct answer was immediately provided. One of the first three trivia questions asked which psychic made the prediction, and since feedback was given, this afforded an opportunity to make more salient the psychic actually associated with the scenario. Following the first three questions, an instruction appeared on the computer screen indicating that an additional four questions would be randomly selected from our pool and that one or more previous questions could be repeated. One of these next four questions asked again about the relevant psychic, and again, feedback was provided. Thus, the probability was quite high that by the end of the learning period, the participants knew with high confidence which psychic made which major prediction and were aware of how strongly they wanted that prediction to be realized.

A 30-min distractor task followed the study period. The participants then took a surprise source test. Each scenario was presented in its original form, with asterisks replacing the psychics' names. The two major scenarios were tested first, in random order, followed by all old and new minor scenarios, in random order. For each scenario, the participants indicated whether Deanna Divine or Heather Heartly made the prediction or whether it was new. No feedback was given concerning accuracy.

\section{Results and Discussion}

Because the wishful thinking effect we were testing for would depend on participants knowing which psychic had made the desirable and undesirable major predictions, we included source monitoring data for minor scenarios only if two criteria held for the major scenarios. First, participants must accurately identify the relevant psychic for both of the major scenarios during the source test. Second, they must express a desire (defined as a rating of at least 5 on the seven-point scale) for the positive major scenario to come true and a desire (defined as less than or equal to 3 ) for the negative major scenario not to come true. Seven participants were excluded based on these criteria.

Recognition for the minor scenarios was near ceiling $(96 \%)$. The low false-alarm levels prevented further analysis of these data for patterns of misattribution.

We examined the data for evidence that wishful thinking distorted people's memory for source in the critical (minor) predictions. Wishful thinking would manifest as a bias to assign accurate predictions for the brief scenarios to the psychic who made the desirable major prediction and to assign inaccurate predictions to the one who made the undesirable major prediction. That is, distortions of individual memories could serve a more global desire for a given source to be reliable or unreliable. Even if the minor prediction involved something mildly unpleasant that then came true, the accuracy of the pre- 
diction would contribute positively to that psychic's overall reliability. Thus, regardless of the valence of the prediction or outcome, participants should be biased to attribute the accurate predictions to the psychic who was associated with the desired major event.

Alternatively, wishful thinking may simply be a special case of schema or halo/devil effects and may not exert complex or global influence on memory (Cook et al., 2003). If this is the case, then only the local valence, and not the accuracy, of a minor scenario should affect source attribution. Positively valenced scenarios (by virtue of either their happy predictions or happy outcomes) should be attributed to the source who had made the positive major prediction (a halo effect), and negative scenarios should be attributed to the source who had made the negative one (a devil effect). Such schema-like effects, although not identical to the one demonstrated by Cook et al., would not require emotional investment in the messages or in source reliability, but could occur because of a simple associative matching process.

An ANOVA on global wishful thinking effects examined source accuracy for the minor scenarios using the factors of desired reliability level (high vs. low, corresponding to one psychic or the other) $\times$ accuracy of minor prediction (accurate vs. inaccurate). This analysis produced a significant interaction, $[F(1,216)=6.79$, $\left.M S_{\mathrm{e}}=1.30, p<.01\right]$. (See Table 4.) In particular, people tended to attribute accurate minor predictions to the psychic who had made a desirable major prediction $(M=$ .56 , compared with .44 for the other psychic) and inaccurate minor predictions to the psychic who had made an undesirable major prediction $(M=.52$, compared with .48 for the other psychic). Both of these are wish-consistent distortions. Thus, wishful thinking can act not only on individual messages but across entire memory sets in order to produce a desired belief.

We also conducted two analyses to test the possibility that a more local, schematic effect leads people to match positivity with positivity and negativity with negativity. An ANOVA with the factors psychic valence (positive vs. negative major prediction) and outcome valence (positive vs. negative minor outcome) showed no significant effects and, in particular, no significant interaction $[F(1,216)<1]$. A second ANOVA with the factors psychic valence and valence of prediction (regardless of outcome) also yielded no significant effects $[F(1,216)<1]$.

Table 4

Source Accuracy Means and Standard Deviations for Minor Scenarios in Experiment 3

\begin{tabular}{lccccc}
\hline & \multicolumn{2}{c}{$\begin{array}{c}\text { High Desired } \\
\text { Reliability }\end{array}$} & & \multicolumn{2}{c}{$\begin{array}{c}\text { Low Desired } \\
\text { Reliability }\end{array}$} \\
\cline { 2 - 3 } \cline { 5 - 6 } & $M$ & $S D$ & & $M$ & $S D$ \\
\hline Correct minor prediction & $.55^{*}$ & $.21^{*}$ & & $.40^{\dagger}$ & $.21^{\dagger}$ \\
Incorrect minor prediction & $.47^{\dagger}$ & $.20^{\dagger}$ & & $.52^{*}$ & $.20^{*}$ \\
\hline * & & & &
\end{tabular}

${ }^{*}$ Wish-consistent conditions. $\quad$ Wish-inconsistent conditions.
Thus, there was no indication of schematic biases that would lead people to match the positively valenced minor scenarios with the predictor of the positive major scenario. Although there is evidence for a global wishful thinking effect (distorting memories in service of creating source reliability), there is no evidence for more local and more simple matching effects. Additional dissociations between our findings and those that typify halo/devil effects are reviewed below.

\section{GENERAL DISCUSSION}

Wishful thinking consistently affected people's performance when they were led to care about the outcome of a situation. The effect occurred whether information about source accuracy was present at encoding or was not learned until retrieval. Wishful thinking appears to be largely dependent on processes at retrieval that either affect the way source cues are processed or act as cues in their own right. When memory for the source of a highly valenced item is too well remembered to be rewritten, the source attribution of entirely unrelated memories can be distorted in order to give the source the appearance of desired characteristics. These findings are consistent with the source monitoring framework's assertion that uncertain sources undergo cue-based reconstruction at retrieval, but they expand on that framework by asserting that this reconstruction need not support the goal of accuracy.

The wishful thinking effect may be related to the choice-supportive biases demonstrated by Mather et al. (2000), who showed that participants attribute positive characteristics to an option they have selected and negative characteristics to a rejected option. As with the present findings, this choice-supportive bias appears to be a retrieval effect. In both cases, participants make source attributions that increase anticipated happiness. However, the choice-supportive effect might be carried by a semirational heuristic (e.g., participants attribute more positive options to their own choices because they believe that they must have made the choice for a good reason). Such a heuristic cannot be used to explain the present findings, in which desire appears to be used as a genuinely nonrational source cue.

A potential alternative explanation for the wishful thinking effect is that participants simply associate positive information with positively portrayed sources (halo effect) and negative information with negatively portrayed sources (devil effect) (Cook et al., 2003). However, in Experiment 3 participants associated negative but accurate predictions with the source of a highly desirable outcome and positive but inaccurate predictions with the source of a highly undesirable outcome, which argues against a schema-based bias. In addition, there are notable dissociations between schema-based effects and the one demonstrated here. Halo and devil effects occur only when valenced source characteristics are described just prior to test. When this information is given 
prior to study (as in Experiment 1 and the encoding condition of Experiment 2), such effects vanish. (See also Hicks \& Cockman, cited in Cook et al., 2003). Since the wishful thinking effect does not follow this pattern, it seems unlikely that a schema-based match between source and scenario valence provides adequate explanation.

The bias to make source decisions that are consistent with one's wishes has practical implications. People sometimes make important life decisions based on information from "experts." Misattribution of inaccurate information to experts can lend it unwarranted plausibility, with serious consequences, as in the example of the cancer patient who pursues a bogus miracle cure. As with other types of source monitoring errors, wishful thinking could also have consequences for eyewitness testimony. Witnesses with a stake in the outcome of a case may be more likely to make reality monitoring errors, genuinely believing they have seen events that support their desired verdict.

Our participants' wishes were strong enough to affect memory for scenarios that were unlikely ever to impact them directly. In contrast, most real-world situations in which wishful thinking might be important would have more direct personal relevance. Such situations would provide an interesting test case for the power of the wishful thinking effect. On one hand, we probably have stronger desires for real-world situations that affect our lives than for fictional stories, and focus on emotion can interfere with the accuracy of source attribution (Johnson, Nolde, \& De Leonardis, 1996). On the other hand, people generally have better memory for self-relevant information (Rogers, Kuiper, \& Kirker, 1977), are better at source monitoring tasks for self-referential statements than for statements that refer to another person (Kahan \& Johnson, 1992), and tend to examine information more closely if it is personally relevant (Prentice, Gerrig, \& Bailis, 1997). Thus, indications from the existing literature are split as to whether self-reference would magnify or reduce the wishful thinking effect, and the answer would have important implications for how source monitoring actually affects people's lives.

In a broader social context, wishful thinking may levy a cost beyond memory accuracy. Self-serving biases in other areas of cognition contribute to such undesirable phenomena as the perpetuation of stereotypes (Allport $\&$ Postman, 1945) and of belief sets that support addiction (Viscusi, 1992), and the bias explored here could easily be turned to these ends. Source identification helps to determine how a memory will be used, and the present work identifies a nonrational mechanism by which a memory's self-serving value is systematically increased.

\section{REFERENCES}

Allport, G. W., \& Postman, L. J. (1945). The basic psychology of rumor. Transactions of the New York Academy of Sciences, 8, 61-81.
Bahrick, H. P., Hall, L. K., \& Berger, S. A. (1996). Accuracy and distortion in memory for high school grades. Psychological Science, 7, 265271.

BENTALL, R. P. (1990). The illusion of reality: A review and integration of psychological research on hallucinations. Psychological Bulletin, 107, 82-95.

Boon, J., \& Davies, G. (1996). Extra-stimulus influences on eyewitness perception and recall: Hastorf and Cantril revisited. Legal \& Criminological Psychology, 1, 155-164.

COOK, G. I., Marsh, R. L., \& HicKs, J. L. (2003). Halo and devil effects demonstrate valenced-based influences on source-monitoring decisions. Consciousness \& Cognition, 12, 257-278.

Dellarosa, D., \& Bourne, L. E. (1984). Decisions and memory: Differential retrievability of consistent and contradictory evidence. Journal of Verbal Learning \& Verbal Behavior, 23, 669-682.

Ditto, P. H., Jemmott, J. B., \& Darley, J. M. (1988). Appraising the threat of illness: A mental representational approach. Health Psychology, 7, 183-201.

GreEne, E. (1981). Whodunit? Memory for evidence in text. American Journal of Psychology, 94, 479-496.

Greenwald, A. G. (1980). The totalitarian ego: Fabrication and revision of personal history. American Psychologist, 35, 603-618.

Hautus, M. J. (1995). Corrections for extreme proportions and their biasing effects on estimated values of $d^{\prime}$. Behavior Research Methods, Instruments, \& Computers, 27, 46-51.

Intraub, H., \& HofFman, J. E. (1992). Reading and visual memory: Remembering scenes that were never seen. American Journal of Psychology, 105, 101-114.

Johnson, M. K., Foley, M. A., \& Leach, K. (1988). The consequences for memory of imagining in another person's voice. Memory \& Cognition, 16, 337-342.

Johnson, M. K., Foley, M. A., Suengas, A. G., \& Raye, C. L. (1988). Phenomenal characteristics of memories for perceived and imagined autobiographical events. Journal of Experimental Psychology: General, 117, 371-376.

Johnson, M. K., Hashtroudi, S., \& Lindsay, D. S. (1993). Source monitoring. Psychological Bulletin, 114, 3-28.

Johnson, M. K., Nolde, S. F., \& De Leonardis, D. M. (1996). Emotional focus and source monitoring. Journal of Memory \& Language, 35, 135156.

Johnson, M. K., \& RaYe, C. L. (1981). Reality monitoring. Psychological Review, 88, 67-85.

Kahan, T. L., \& Johnson, M. K. (1992). Self effects in memory for person information. Social Cognition, 10, 30-50.

Kunda, Z. (1990). The case for motivated reasoning. Psychological Bulletin, 108, 480-498.

Macmillan, N. A., \& Creelman, C. D. (2004). Detection theory: A user's guide (2nd ed.). Mahwah, NJ: Erlbaum.

Marsh, R. L., Landau, J. D., \& Hicks, J. L. (1997). Contributions of inadequate source monitoring to unconscious plagiarism during idea generation. Journal of Experimental Psychology: Learning, Memory, \& Cognition, 23, 886-897.

Mather, M., \& Johnson, M. K. (2000). Choice-supportive source monitoring: Do our decisions seem better to us as we age? Psychology \& Aging, 15, 596-606.

Mather, M., Shafir, E., \& Johnson, M. K. (2000). Misremembrance of options past: Source monitoring and choice. Psychological Science, 11, 132-138.

Mather, M., Shafir, E., \& Johnson, M. K. (2003). Remembering chosen and assigned options. Memory \& Cognition, 31, 422-433.

Miller, J. (1996). The sampling distribution of $d^{\prime}$. Perception \& Psychophysics, 58, 65-72.

MorRISON, A., \& HADDOCK, G. (1997). Cognitive factors in source monitoring and auditory hallucinations. Psychological Medicine, 27, 669-679.

Perloff, L. S., \& Fetzer, B. K. (1986). Self-other judgments and perceived vulnerability to victimization. Journal of Personality \& Social Psychology, 50, 502-511.

Prentice, D. A., Gerrig, R. J., \& Bailis, D. S. (1997). What readers 
bring to the processing of fictional texts. Psychonomic Bulletin \& Review, 4, 416-420.

Rogers, T. B., Kuiper, N. A., \& Kirker, W. S. (1977). Self-reference and the encoding of personal information. Journal of Personality \& Social Psychology, 35, 677-688.

Ross, M., McFarland, C., \& Fletcher, G. J. (1981). The effect of attitude on the recall of personal histories. Journal of Personality \& Social Psychology, 40, 627-634.

Sherman, J. W., \& Bessenoff, G. R. (1999). Stereotypes as source- monitoring cues: On the interaction between episodic and semantic memory. Psychological Science, 10, 106-110.

TAYLOR, S. E. (1989). Positive illusions: Creative self-deception and the healthy mind. New York: Basic Books.

VISCUSI, K. (1992). Smoking. Oxford: Oxford University Press.

Weinstein, N. D., \& KleIN, W. M. (1996). Unrealistic optimism: Present and future. Journal of Social \& Clinical Psychology, 15, 1-8.

Woike, B., \& Polo, M. (2001). Motive-related memories: Content, structure, and affect. Journal of Personality, 69, 391-415.

\section{APPENDIX A \\ Examples of Experiment 1 Stimuli}

All participants first read the Introduction (shown below in its entirety), followed by 20 premanipulation scenarios ( 6 of which are presented here). Then each participant read 10 undesirable, 10 desirable, and 10 neutral experimental scenarios; examples of each are given below.

Introduction

1-800-FUTURES is a small psychic hotline that employs 2 fortune tellers. People calling them up ask a variety of questions ranging from the personal to the political.

Anna Ashland is remarkably accurate. Whether through luck or actual psychic ability, she manages to be correct with most of the predictions she makes.

Candy Carson, while a good actress, is a terrible fortune teller. Although she believes strongly in her own intuitive powers, most of the time her predictions fail to come true.

Premanipulation scenarios, with outcomes (to establish Anna as a good and Candy as a bad psychic). One or the other psychic was associated with each scenario so that each participant read 8 accurate and 2 inaccurate predictions by Anna and 8 inaccurate and 2 accurate predictions by Candy.

The U.S. appointed a new, relatively unknown ambassador to deal with a war in New Azlan. [Psychic] predicted that he would manage to solve the problem. Shortly after he arrived, he began talks between the two rival groups that resulted in a treaty.

Flooding in the Midwest caused a rise in homelessness in that area. [Psychic] predicted that Congress would vote extra money for aid within a month. However, the vote was tied up in details, and a month later nothing had yet been decided.

A talk-show host gave away several rare Beanie Babies in a raffle. [Psychic] predicted that the contest would do his reputation more harm than good. Shortly thereafter, the Beanie Babies were proven to be fakes, and his show was pulled from the air.

Barnett Robotics planned to open a new factory in a poor neighborhood in Boston. [Psychic] predicted that the factory would have long-term benefit for the area's economy. However, within a year the factory had been abandoned half-built.

Congress spent several months debating the pros and cons of a minimum wage increase. [Psychic] predicted that the increase would be passed into law. After the debate was finished, the rate was increased by 1 dollar.

An experimental measure was passed to legalize gambling in California. [Psychic] predicted that when they saw the results, other states would begin to copy the law. However, the California law resulted in problems with organized crime, and rather than being copied by other states the original was repealed within the year.

Experimental scenarios, presented as a single paragraph with an opening description that makes the prediction either desirable or undesirable, followed by the prediction itself.

Desirable: The Sienna Fern is a plant whose leaves can be used to ease allergy symptoms. It also contains a substance in its pollen which repels mosquitoes.

Undesirable: The Sienna Fern is a weed to which many people are allergic. It also contains a substance in its pollen that increases the breeding rate of mosquitoes.

Prediction: [Psychic] predicts that this plant, which is at present relatively rare, will begin growing in higher numbers in urban areas.

Desirable: Up-and-coming rap group, 2-B-Low, have just announced that $10 \%$ of all their profits will go to the American Association of Women's Shelters. They are currently looking for a contract with a music company to promote their new album. 


\section{APPENDIX A (Continued)}

Undesirable: Up-and-coming rap group, 2-B-Low, have publicly made sexist and racist remarks, including suggesting that they give some of their profits to the Ku Klux Klan. They are currently looking for a contract with a music company to promote their new album.

Prediction: [Psychic] predicts that L.A. Productions will add a new name to their record label, 2-B-Low, and will help the group produce new singles.

Desirable: Elvis Airlines, which has had suspended service for several months while they fixed problems caused by internal incompetence, is attempting to get permission to reopen.

Undesirable: Elvis Airlines, which has had suspended service for several months while they fought off false accusations of incompetence from a competitor, is attempting to get permission to reopen.

Prediction: [Psychic] predicts that they will not be allowed to resume their flights.

Desirable: Jerry Matt, a Harvard senior whose GPA hovers between 2.99 and 3.01, hires honor students to take exams for him, while he spends his nights partying. Jerry wants to apply to the Honors College of Economics and Business, which has a minimum GPA requirement of 3.00.

Undesirable: Jerry Matt, a Harvard senior whose GPA hovers between 2.99 and 3.01, is vice-president of the student body and has double-majored in Business and Economics. Jerry wants to apply to the Honors College of Economics and Business, which has a minimum GPA requirement of 3.00.

Prediction: [Psychic] predicts that his final GPA will be 2.99 .

Desirable: Patty Levine's husband was caught stealing and sentenced to 5 years in prison for minor theft. He was stealing the money in order to buy medicine for Patty, who has terminal cancer. She is afraid that she will not survive to see him released.

Undesirable: Patty Levine's husband was caught stealing and sentenced to 5 years in prison for minor theft. Before going to jail, he had abused Patty, and she testified against him at the trial. She is afraid that when he is released he will come after her.

Prediction: [Psychic] predicts that new evidence will cause him to be retried and released early.

\section{Neutral Items}

The Billboard group is tabulating rock song requests for this week's Top 40. Several new groups have put out songs this week, and everyone is wondering which ones will make the list. [Psychic] predicts that Flying Squid's song "Buying Back the Blues" will get a spot in the Top 10.

Julian Barclay, an excellent chef who has just completed his training, wants to open an unusual restaurant and is trying to figure out what kind will be the most profitable. He has narrowed his choices to Romanian food and Nepalese. [Psychic] predicts that the next few years will see an increased trend for Romanian food, while Nepalese will remain unpopular.

Christie's is auctioning off a collection of old Beatles memorabilia. The collection includes several stage costumes and pieces of musical gear. [Psychic] predicts that the piece that will sell for the most will be a drumstick used in their first concert.

The postal service is deciding what flowers to put on their new spring stamps. [Psychic] predicts that one of the flowers will be a tulip.

A treaty has been proposed in war-torn Latvenia that would divide territory between the rebel guerrillas and the ruling government. The talks are stalled over several minor points, including the location of the proposed embassy and the language in which the final treaty is to be written. [Psychic] predicts that the embassy issue will take longer to resolve than the language issue.

\section{APPENDIX B \\ Examples of Experiment 3 Stimuli}

\section{BRIEF SCENARIOS (Critical Items)}

\section{Accurate Predictions}

Locally desirable (accurate prediction of good minor outcome): Julie Chester works in a clothing boutique downtown and does not own a car. Although it is somewhat expensive, Julie takes a taxi to and from work every day. To offset rising fuel costs, the Nice Ride taxi company considered an increase in the price of their fares. [Psychic] predicted the rates would not go up. Outcome: Due to public opinion, Nice Ride decided to maintain their current fares. 


\section{APPENDIX B (Continued)}

Locally undesirable (accurate prediction of bad minor outcome): Claire Franks had her 10th birthday coming up and had asked her parents for a toy she had wanted for several months, the Chatty Cathy Doll, that can say ten different phrases. [Psychic] predicted that Claire would not get the doll. Outcome: Claire got a new sweater for her 10 th birthday.

Locally neutral (accurate prediction of neutral minor outcome): The Spotted Flyer is a pond grazing bird. It uses its long tail feathers to fly south for the winter. The number of tail feathers changes from year to year, depending on the severity of the weather. [Psychic] predicted that the Spotted Flyer would have 6 tail feathers this year. Outcome: The Spotted Flyer had 6 tail feathers.

\section{Inaccurate Predictions}

Locally desirable (inaccurate prediction with good minor outcome): Chris Crusher was making his television debut as a professional wrestler. He wanted to program his VCR to tape his performance and show his friends. Unfortunately, his VCR was old and often malfunctioned. [Psychic] predicted that the VCR would malfunction and that Chris would not be able to tape his performance. Outcome: Chris's VCR worked, and he was able to tape his performance.

Locally undesirable (inaccurate prediction with bad minor outcome): Tammy was getting ready to start a new job. Because they had to move to another state, Tammy and her husband could not take most of their furniture with them. She was hoping that she would get an advance in salary from her new job so that she could buy a new kitchen table. [Psychic] predicted that Tammy would get the advance. Outcome: Tammy did not get the advance in her salary and was unable to buy a new kitchen table.

Locally neutral (inaccurate prediction with neutral minor outcome): Two rival groups of archaeologists were involved in an expedition in Egypt for some rare hieroglyphics but were having a debate about their actual age. The Green Team believed the stone to be 2,000 years old. The Blue Team believed the stone to be 3,000 years old. [Psychic] predicted the Blue Team was right. Outcome: The stone was found to be 2,000 years old, confirming the Green Team's assessment.

\section{MAJOR SCENARIOS}

These two scenarios, one assigned to each psychic, were overlearned and were designed to produce strong wishes concerning the relative reliability of the two psychics.

\section{Inducing a Strong Wish for Reliability}

Researchers at a prestigious drug company have been working on developing a new cancer drug that, if successful, will significantly shrink previously inoperable large tumors so that they can be easily removed, saving thousands of lives. Dr. Silvia Barnett, a researcher at Drugco Research Foundation, has worked tirelessly for 10 years to perfect this powerful cancer-fighting drug. As a small child, Dr. Barnett lost her mother to inoperable breast cancer. Two years ago, she was diagnosed with breast cancer herself, but it is in remission. Researchers in France have isolated the exact chemical compound necessary to synthesize the drug, and production is already underway in Europe. Once in production, the drug is expected to save 500,000 lives in the United States annually. However, the synthesis of this drug requires the use of chemical compounds that are considered illegal in the United States, and the FDA has banned the manufacture of this drug. Dr. Barnett has been actively involved in formulating legislation that would lift the ban on the manufacture of this life-saving drug. The Barbara Bill, named in honor of her mother, has been brought before the House of Representatives and is ready for a vote.

A call was received today on the psychic hotline by [Psychic], and the caller wanted to know her prediction regarding this bill. [Psychic] knew that this was one of the most important predictions she would ever make in her career, realizing the impact that this situation would have on hundreds of thousands of people. [Psychic] took her time consulting her indicators for the future. After deliberating carefully, [Psychic] predicted that the legislation will pass and production of the life-saving drug will begin.

\section{Inducing a Strong Wish for Unreliability}

Jeffrey Jones is a college student just finishing up his final semester at a prestigious university with a 3.9 GPA and many academic honors. However, he does not deserve these honors. Early in his career, he found it tough to keep up with his studies and quickly found his grades slipping in his highly competitive pre-law program. He knew that the only way to ensure a high paying job was to do well in his courses and earn good grades. He had heard of people buying tests and papers and succeeding through college, and he decided to try it. He bought a term paper, handed it in, and received an A+. Soon, instead of spending more time studying, he found that he could easily buy his term papers and exams online, and he began to cheat in all of his courses. 


\section{APPENDIX B (Continued)}

His grades shot up and he quickly wound up at the top of his class while smarter and more honest people struggled through their studies and earned much lower grades. He soon discovered his real talent for cheating and his pleasure in finding ways to do it, just for the fun and the challenge of it. He enjoys dominating and achieving gains he doesn't deserve, even if he doesn't really want them. Jeffrey has recently applied for a job at a prominent humanitarian law firm that prides itself on the honesty and integrity of its workers and hires only two graduates nationally every year. He is attracted to this firm because it trusts its employees and does not monitor their actions closely, so he would be in a good position to steal money from clients and to make illegal deals with contractors. On his application to the law firm, Jeffrey lied about his credentials and included fake letters of recommendation to make himself look better. As a result of his high GPA and apparent superior credentials, Jeffrey has been granted an interview for the job.

[Psychic] received a call on the psychic hotline this morning asking for her prediction about whether Jeffrey would get the job. [Psychic] knows that the outcome of the interview process is important and that the integrity of this very upstanding and socially conscious law firm is at stake with every hire they make. When the call came in this morning, [Psychic] was very careful in consulting all of her psychic indicators. After much deliberation, [Psychic] predicted that the law firm will be impressed with Jeffrey at the interview and will offer him the job.

(Manuscript received June 20, 2003;

revision accepted for publication July 14, 2004.) 